\title{
A Research Review of College English Audio-Visual Speaking Teaching in China in Multi-Modality Symbol Framework
}

\author{
Dan Yang ${ }^{1}$ \\ ${ }^{1}$ Associate Prof., Foreign Language School, Yancheng Teachers' University, Yancheng, Jiangsu, China \\ Correspondence: Dan Yang, Foreign Language School, Yancheng Teachers' University, Yancheng, Jiangsu, \\ China. E-mail: 409760370@qq.com
}

Received: September 11, 2019 Accepted: October 10, 2019 Online Published: November 14, 2019

doi:10.5539/ells.v9n4p39 URL: https://doi.org/10.5539/ells.v9n4p39

\begin{abstract}
In the past ten years, on the background of multi-modality symbols, researches of college English audio-visual speaking teaching in China have transitioned gradually from theoretical researches to practical researches in the aspect of research methods and research priorities. Five pairs of relationships between multi-modality symbols and college English audio-visual speaking teaching have been concerned about. When applying multi-modality symbols into college English audio-visual speaking teaching, teachers should choose different modals and teaching content appropriately, should use multi-modal languages comprehensively, should stress students' self-study management, should speed up multi-modal teaching platform construction and use, should apply dynamic teaching and management mechanisms, and should construct a comprehensive teaching and evaluation mechanism.
\end{abstract}

Keywords: multi-modality symbol, audio-visual speaking teaching, teaching model, multimedia

\section{Introduction}

The multi-modality discourse theory began from the 90s of the last century, which was a new discourse analysis theory. The multi-modality analysis avoids a single language form as the research object and this theory neglects the limits of other modals such as sound, pictures, colors etc., combining other modal interrelationship devices into the language research. The multi-modality symbol refers to the diverse symbol modalities in a complex product or a communication activity (van Leeuwen, 2005, p. 281). It also refers to making use of different symbol resources in a specific text in order to construct meanings (Baldry \& Thibault, 2006, p. 21). The music, image and other visual symbols, which were traditionally considered non-languages or sub-languages, are now working together to construct meanings. The multi-modality teaching was a new concept put forward by the New London Group in 1996. As a teaching concept, it stresses multiple abilities of learners, advocating using the internet, pictures and role play and multiple teaching means to attract learners' senses to work together in language acquisition. In the multi-modality teaching process, students perceive, understand, code and deposit information and make foundations for meaningful and automatic production, which form a cycling system. Such cycling benefits knowledge acquisition, memory and cognition improvement. Zhang holds that multi-modality communication gets the listeners to acquire information by more channels, which make it easier for listeners to understand and memorize information (2010, p. 52). Long and Zhao hold that transitions between modalities are possible, so multi-modality teaching is effective for language acquisition (2009, p. 59).

The English audio-visual speaking teaching, different from the traditional single-language modal or the occasionally used non-language modal such as the gesture, is a new educational modal under the modern teaching technology and multi-media environment. In this new teaching scenario, modals are increased, to increase the classroom teaching, attracting students' more attention. The audio modal symbols and visual modal symbols are the most important modal symbols in audio-visual speaking teaching. In the classroom, the teacher and students' oral language as well as their tones, tunes, intonation, frequency all belong to audio modal symbols. The image, charts, objects, videos, facial expressions, dressing, gestures and scene arrangement (such as power point and the blackboard content) all belong to visual modal symbols. Besides audio symbols and visual symbols, human's other perception systems consist of smell, taste and smell modals. In fact, the audio-visual speaking teaching isn't usually represented by the single modal form, as the single-modal form is tedious, making lessons boring. Therefore, two or more modal symbols interact in one lesson. For instance, when teaching about the 
western festival Halloween, the teacher would use the power point, introducing the sources and customs by formal language. Besides, the teacher uses pictures to present the features of the festival, such as the ghost-shape pumpkin lamp, white-net black spider and sweets. In addition, the teacher inserts music in the power point to get students to enjoy the Halloween songs or get students to make emblems or costumes for the Halloween, eating festival food, making students feel western Halloween from audio, visual, taste, tactile senses. The combined uses of muti-modals are the main forms of the audio-visual speaking teaching (Wang, 2013).

Currently, the Chinese scholars like Gu (2007), Zhang (2009), Zhu (2007) applied this theory into foreign language teaching. The teaching methods on the background of multi-modality theory were based on the multi-modality discourse analysis from systematic functional linguistics, which has been applied in college English audio-visual speaking teaching a lot. In CNKI (China National Knowledge Infrastructure), the author consulted 85 articles related to "multi-modality" and "audio-visual speaking teaching". As SSCI (Social Sciences Citation Index) source journals, core journals and CSSCI (China Social Sciences Citation Index) journals could represent the forefront and development of the academic circles in China, these are listed as sifting conditions. The author found five related articles altogether and he realized that the scholars were most concerned about class interaction (Wang, 2013), effectiveness of listening and speaking ability development (Zeng, 2011), teaching design (Jiang, 2013), teaching material design (Liu, 2011) and teaching model (Xun, 2013).

The author intended to probe into the latest researches on five pairs of relationship between multi-modality symbols and college English audio-visual speaking teaching, including multi-modality symbols and class interaction, multi-modality symbols and listening and speaking ability development effectiveness, multi-modality symbols and teaching design, multi-modality and teaching models and found that much progress has been achieved in this regard.

\section{Five Pairs of Relationships Between College English Audio-Visual Speaking Teaching and Multi-Modality Symbols}

\subsection{Relationship Between Multi-Modality Symbols and Class Interaction}

Class interaction refers to a process in which teachers and students communicate thoughts and emotions, convey information and affect each other. Multi-modality teaching in the multi-media environment means good interaction among multi-modalities between teacher-student, student-student, teacher/student-language corpora. A good class interaction benefits language study and development (Wang, 2013).

A good class interaction has special importance in the background of internet plus. First of all, good class interaction benefits improving teacher-student relationship, improving students' language output ability. Secondly, good class interaction benefits securing timely feedback of teaching information, keeping teachers adopting appropriate teaching materials and using correct teaching methods to give lessons. Finally, good class interaction benefits intriguing students' study interest, enhancing their class interaction consciousness and teamwork ability. However, current multi-modality classes have some problems, harmful to students' language study and development. Firstly, teaching materials and corpora are selected simply, useless for students' listening and speaking ability improvement. Secondly, the class depends too much on the multi-media, basically not different from traditional one-modal teaching. Teachers move little, distancing from students, which is harmful to effective communication. At last, teachers' questions can't introduce students' good language output, so students' language output is simple (Zhang, 2009)

Therefore, Wang (2013) pointed out that audio-visual speaking teaching classes under multi-modality condition should at least consist of class interactions in audio-symbols, in visual-symbols and in other-modal symbols. The Class interaction in audio-modal symbols consists not only of verbal language symbols uttered by teachers and students, but also of other audio-symbols, the most typical of which is the listening materials broadcast by multi-media devices. The teacher-student interaction in class using audio-modal symbols should be made full use of, so as to increase effective interaction between teacher-student, student-student and teacher/student-corpora. The teacher-student interaction in visual-modal symbols consists of two parts. One is the interaction using written language symbols, including PPT or blackboard writings. The other is image symbols such as pictures and cartoon pictures. In the audio-visual speaking class, the interaction based on audio-modal symbols should be at a prominent position, and the one based on visual-modal symbols should be in a subsidiary position, which is the necessary enhancement and supplement to the one on audio-modal symbols. The class interaction based on other modal symbols, including smelling, touching, tasting perceptions from interaction or virtual performances between teacher-student and student-student, are the supplement of the interaction based on audio-modal and visual-modal symbols. The interaction based on other modal symbols increase the vividness of a class. To sum up, the interaction based on multi-modal symbols needs cooperative work in the class teaching before it produces 
profound significance and achieves good teaching effects (Wang, 2013).

\subsection{Relationship Between Multi-Modality Symbols and Listening Speaking Ability Development Effectiveness}

The traditional college English audio-visual speaking teaching is fixed in content and form and students have too much freedom in self-study. Based on this problem, Chongqing Transportation University had reforms towards audio-visual speaking course, taking the teaching model based on multi-modal model, with the aim to improve students' listening and speaking abilities. They took an exploratory experiment to test its feasibility and rationality. In order to make the experiment more persuasive, the experiment analyzed the entrance exam test scores of the experiment class and control class. They also made questionnaires for both classes. By comparing scores before and after the experiment for both classes, their results showed that the audio-visual speaking teaching based on multi-modal symbols helped students accumulate rich writing materials in listening, speaking and reading process. Listening promoted speaking, reading and writing by inputting topic-related listening, watching, oral and reading materials, which achieved systematization of input and output. Cycled input and output based on the same topic enhance the students' language sensitivity, effectively promoting the process of students' controlling and internalizing language. The questionnaire result analysis showed that audio-visual speaking teaching model based on multi-modality symbols produced desirable feedback effect. Maclntyre\&Noels held that the audio-visual listening teaching model based on multi-modality symbols helped with students' self study, the understanding and mastering studying process, reducing anxiety and confusion, keeping enthusiasm and motive or improving study attitude and studying motivation (1996). The questionnaires checked the positive effects of the teaching model on students' learning effect. Overall, the audio-visual speaking teaching model based on multi-modality symbols improved students' listening and speaking abilities, English comprehensive abilities and self-study ability.

\subsection{Relationship Between Multi-Modality Symbols and Teaching Design}

In the combination between multi-modality symbols and audio-visual speaking teaching, three aspects must be noticed (Jiang, 2013). First of all, teaching designers should use meaning based on all modals to convey meaning. Regarding different teaching purposes, multi-modal resources brought by new technology should be investigated, multi-modal symbols resources should be selected effectively and arranged accordingly and appropriate audio-visual activities should be designed for learners to select different modal symbol systems to participate in practice activities in order to become conscious study subjects. Secondly, teaching designers should make full use of performing and communicative models in teaching designs. Two models are on the same level, with different purposes, its key lying in selecting and arranging appropriate modal resources based on learners' needs, teaching content and teaching goals, so as to promote learners to make full use of the current multi-modal resources. Finally, from the perspective of multi-modality, teaching is not the process for students to accumulate and acquire symbols and meanings, but a process for teacher and students to mark multi-modal symbols and make new interactive meanings driven by mutual interests and teaching purposes. From the perspective of cognitive psychology, modal transfers are feasible and effective for language study (Long, 2009). Compared with the traditional single-modal study, multi-modal teaching improves students' active application of all senses to manage, deposit and output the information input, so promoting multi-language skill internalization. Jiang used teaching cases to interpret that all activities of teaching sessions need combining multi-modal symbols through multi-modal teaching design before class, multi-modal teaching design in class and multi-modal teaching design after class. In this way, students are involved in the education interaction situations and the construction of teaching interaction meanings. On the background of audio-visual speaking teaching under multi-media technology and internet technology, multi-modal audio-visual speaking teaching design helps teachers to manage the relationship between teacher/student and the computer so as to arrange teaching resources with advanced technology for the sake of teaching efficiency (Jiang, 2013).

\subsection{Relationship Between Multi-Modality Symbols and Teaching Material Design}

The teaching material has been the difficulty for English audio, visual and speaking course. Looking chronologically at the prevailing methodologies in different periods, people's attention on this course has been improving gradually, and appropriate teaching materials help to improve learners' listening levels a lot (Zhang, 2009). Since the Reform and Opening policy in 1978, direct method, grammatical teaching method, listening and speaking go first, interactional teaching method have begun to receive more and more focus (Xie, 2010). With higher requirements towards practical language abilities, the audio-visual speaking teaching material construction has been more prominent and important. In recent years, scholars have been trying to research and assess college English audio-visual speaking teaching materials from relevant assessment theories, which commonly view that the traditional teaching materials have much to improve (Zuo, 2009). 
The current audio-visual speaking teaching material problem lies not in multi-modality writing concept but in basic attributes, such as teaching content, teaching method and study strategy, mainly in the following aspects (Liu, 2011). Listening materials are lacking in authenticity, practice form is tedious, igniting no interest from students, and self-study is lacking in maneuver. Categories are tedious, with simple modal and form, teaching content is far from reality, practice isn't feasible enough to cultivate students' communication abilities based on future real language environment (Jin, 2008). Low percentage of teaching materials isn't beneficial for achieving course goal or exerting modern information technology functions (Chen, 2007). On the background of multi-modality, the audio-visual speaking teaching materials should be written according to the following principles: multi-dimentsional way, informatization, self-study, openness and ecologicalization. In order to be suited for teaching material principle, based on the special features of multi-modal teaching materials like advanced technology, huge information, convenience and novel forms, the following requirements should be adhered to in content: versatile material, vivid content full of thoughts and plots, full interaction between content and users. Multi-modal foreign language audio-visual speaking teaching material construction should be on the basis of absorbing rational cores of all theories (such as task-oriented study in constructivism, imitation and practice in behaviorism, language information management mechanism in cognitionism, input hypothesis in second-language acquisition theory and interaction in interactional theory), arranging various, vivid, interesting and interactional corpora, which is short for "multi-media, multi-environment and multi-modality" college English audio-visual speaking teaching material (Liu, 2011).

\subsection{Multi-Modality Symbols and Teaching Model}

College English audio-visual speaking class should satisfy the needs of cultivating learners' multimodal literacy, reforming teaching models constantly, adopting a teaching model focusing multimodal corpora input and literacy cultivation, so as to satisfy language learning requirements of the new age (Xun, 2013). Multimodal teaching methodology holds that language, image, sound, motions are all sources of meaning construction, multimodality symbols should be made full use of cooperatively in teaching and multimodal teaching should be carried out with language cognition rules. Firstly, teaching conceptions should be transferred improve multimodal teaching abilities. It has three requirements, including changing teachers' roles, from instructors to constructors, from teachers to cooperators and guides, from the wise on the stage to instructors on the side; enhancing class cooperation multimodality application abilities, changing from teaching to displaying; overcoming limits of multimedia devices, creating multimodality communication atmosphere. Secondly, teaching materials should be organized rationally, exerting supplementary roles of all modalities. This aspect has three requirements, including power point document multimodality display on the basis of cognition rules, power point documents focusing joint meaning construction of multimodality materials, cultivating students' multimodality literacy ability, igniting their metaphor cognition ability by material organization. Thirdly, multimodality teaching activities of audio-visual speaking course can be achieved in the order of topic design-brief instruction - situation practice - critical assessment - restructured practice. This aspect includes the following points. In the session of topic design, teacher and students negotiate about the task topic and achieve congruity. In the session of the brief instruction, the teacher gives definite instructions on task amount and requirements and he also provide a framework for students to accomplish an activity. During this session, resources and the topic should be collocated, so that audio-video modal symbols can be intensified with each other. In the session of situation practice, it means students display the task. According to the multimodality principle, teacher's positive intervention and involvement should be put in this session, the teacher giving timely feedback to students' performance, helping students improve defected expressions and filling students' expression gaps to promote their task accomplishment. The critical assessment consists of assessment of the situation practice between the teacher and students. They give critical assessment on the meaning, context, discourse and linguistic features of the knowledge they have learned, to train students' critical mentality. In restructured practice sessions, it's based on the above sessions and it gives an expansive improvement towards the task and gives another display, helping with students' study experience and thus the teacher can assess students' multimodal literacy ability development (Xun, 2013).

\section{Conclusion: Criticism and Outlook}

In the past ten years, the college English audio-visual speaking teaching research has transitioned from theoretical introductions to class practice research, angles gradually from theoretical interpretation to case studies. Research methods are becoming more vivid and versatile, including questionnaires, interviews, experiments and internet surveys. Researches cover class interaction, listening and speaking ability development, teaching design, teaching material design and teaching models.

When having a outlook at the combination of multimodality symbols and audio-visual speaking teaching 
researches, we realize that just as Gu has said that, multimedia and multimodality teaching are like a two-bladed sword, with good use of which learners' attention can be focused on knowledge so as to enhance memory and improve study effects, or learners' attention will be distracted and knowledge point memory will be interfered with (Gu, 2007). Therefore, teachers should make use of the multimodal audio-visual speaking model scientifically. First of all, teachers should set an appropriate proportion, or a large amount of multimedia information is abundant in class, distracting students' attention and making it difficult for them to digest. Teaching content should be selectively chosen, topic-related and in the order of easiness to difficulties. Secondly, teachers should try to make full use of multimodality language comprehensively, such as correct linguistic form, tone, facial expression and gestures to attract students' attention, to help students understand teaching content deeply. Moreover, teachers should gradually make themselves on the background, push students to the front, help students initiatively display what they've been good at, so as to perceive and apply information. Teachers should learn to convert their roles and provide opportunities for students to practice and make them become starter of audio-visual modality symbols rather than recepients. Thirdly, self-study management should be intensified and improved. From the current status of English teaching and students' study, students can't have all self-study autonomy, as most students aren't eligible to do self-study tasks all by themselves (Shu, 2004). Therefore, the teacher should make detailed course study requirements, make use of management platforms to maneuver students' study process and monitor students' learning process. Fourthly, multimodal teaching platforms must be sped up for the construction and use to promote college English audio-visual speaking teaching development as well as the college English reforms. Fifthly, a dynamic teaching management mechanism should be constructed. The internet teaching management system should be made full use of to maneuver students' internet study and teachers' guidance. Sixthly, a comprehensive teaching assessment mechanism, including a formative assessment and finalized assessment should be constructed in order to test students' self-study and English listening and speaking ability. Among them, the formative assessment concerns study time, study process and study effect, help students' study and applications, which are promoting each other, giving feedbacks to studies; while finalized assessment stresses testing students' ability to apply English listening and speaking skills into practice.

\section{References}

Chen, J. L. (2007). College English Teaching Material Current Status-The Fifth Generation Teaching Material Research and Development Design (vol. 5, p. 374).

Dingfang Shu, D. F. (2004). Foreign Language Teaching and Reforms: Problems and Solutions (p. 15). Shanghai Foreign Language Education Press.

Gu, Y. G. (2007). A Study of Multimedia and Mulmodalities. Foreign Language Audio-visual Teaching, 2, 3.

Jiang, Q. Y. (2013). An English Audio-visual Speakng Teaching Design Probing on the Perspective of Multimodalities. Teaching and Management, 3, 144.

Jin, F. (2008). Analysis and Assessment of Linear College English Listening Teaching Materials. Hangzhou: Zhejiang University Press.

Liu, M., \& Hu, J. S. (2011). Multimodality Design and Requirement Analysis. Foreign Language Audio-visual Teaching, 3, 3 .

Maclntyre, P. D., \& Noels, K. A. (1996). Using Social Psychological Variables to Predict the Use of Language Learning Strategies. Foreign Language Annuals. https://doi.org/10.1111/j.1944-9720.1996.tb01249.x

Qi, D. H. (2014). A Probing into College English Audio-visual Speaking internet Teaching System. Foreign Language Audio-visual Teaching, 12, 71.

Wang, L. (2013). Class Interaction Analysis in Multimodality English Audio-visual Speaking Classes. Teaching and Management, 5, 141.

Xie, J. X. (2010). Jianqiao Dong. On College English Listening Teaching in Multi-media and Multi-modality. Foreign Language Electronic Teaching, 6.

Xun, Y. B. (2013). Enforcement of English Audio-visual Speaking Teaching. Education and Career, 5, 151.

Zeng, Q. M. (2011). An Effectiveness Study of Multimodality Audio-visual Speaking Teaching Model onto Listening and Speaking Ability Development. PLA Foreign Language College Journal, 11, 72.

Zhang, D. L. (2009). A Comprehensive Theoretical Framework Probing of Multimodality Discourse Analysis. China Foreign Language, 1, 24. 
Zhang, H. F., \& Zhao, X. Q. (2009). Improment of College English Listening Teaching Material Analysis and Teaching Methodology. Xian Social Sciences, 5.

Zhu, Y. S. (2007). Theoretical Basis and Research Methods of Multimodality Discourse Analysis. Foreign Language Journal, 5, 82.

\section{Notes}

Note 1. Affiliated Project 1: Univeristy Brand Construction Project in Jiangsu, Phase One (Project Number: PPZY2015A012).

Note 2. Affiliated Project 2: Yancheng Teachers University Teaching Reform Project (Project Number: YCTCJY026).

Note 3. Affiliated Project 3: Jiangsu Provice Teaching Reform Project (Project Number: YT201909).

\section{Copyrights}

Copyright for this article is retained by the author, with first publication rights granted to the journal.

This is an open-access article distributed under the terms and conditions of the Creative Commons Attribution license (http://creativecommons.org/licenses/by/4.0/). 